\title{
Fatigue strength of high strength steel sheets joined by hemming process
}

\section{ZAMZURI Hamedon ${ }^{a,{ }^{*}}$, KEN-ICHIRO Mori ${ }^{\text {, }}$ YOHEI Abe ${ }^{b}$}

\author{
${ }^{a}$ Faculty of Manufacturing Engineering, University Malaysia Pahang, \\ 26600 Pekan, Pahang, Malaysia \\ ${ }^{b}$ Department of Mechanical Engineering, Toyohashi University of Technology, 1-1, \\ Tempaku-cho,Toyohashi, 441-8580, Japan
}

aZamzuri@ump.edu.my

\begin{abstract}
Keywords: Hemming; High strength steel sheet; Hollow section; Fracture; Springback.
\end{abstract}
\begin{abstract}
It is strongly desirable for the vehicle to improve passenger safety and at the same time to reduce the weight of the vehicles. A hollow section for the body structure of automobiles is studied. A high strength steel sheet is used to make the hollow sections in this studied, which are typically joined by resistance spot welding have insufficient energy absorption because the joins are not continuous. Thus, to overcome this problem, the hollow section is joined using the hemming process. The high strength steel hollow sections joined by hemming and resistance spot welding were then examined by tensile and fatigue tests. The hollow section with hemmed joins showed better performance in both tests. The overlapping joins of the hemmed hollow section have greater strength as compared to the resistance of spot welding joins.
\end{abstract}

\section{Introduction}

Since the number of vehicles is increasing over the last two decades, the number of accident and injuries are also increasing. For that, it is strongly desirable for the vehicle to improve passenger safety and at the same time to reduce the weight of the vehicles. Merklein [1] has suggested applying bulk-forming operations to sheet metals to produce high quality sheet metal components with heavily loaded functional elements. Continuous researches are carried out in optimizing the design of vehicle body structure to obtain efficient energy absorbent parts during accident and to protect the user of the vehicle. The hollow sections or tubes with different shape are used extensively as the energy absorbers in most of the vehicles. The hollow sections, which are typically joined by resistance spot welding have insufficient energy absorption because the joins are not continuous. Hamedon et al. [2] believed the laser welding is a better approach to overcome this problem. They also believe that high heating temperature reduces the quality, accuracy and reliability of joined parts. In order to overcome this problem, the hollow section was joined using the hemming method. However, designing the hemmed part is not easy and is influenced by the mechanical properties of the bended part. The main problem for the automotive industry is to bend the high strength steel sheets. For the high strength steel sheets, the dimensional accuracy of formed products deteriorates due to large springback and die deflection, and the formability is small. Mori et al. [3] improved the expansion of a hole of a punched ultra-high strength steel sheet by smoothing fracture surface of the sheared edge using a conical punch. Abe et al. [4] developed a gradually contacting punch to increase the stretch flangeability of the ultra-high strength steel sheets. Maeno et al. [5] used resistance heating to form a low ductility sheet, titanium alloy sheet. The design of stamping processes of high strength steel sheets becomes difficult. Hence, hemming the high strength steel sheets becomes more difficult due to its susceptibility to strain localization during the process. This will cause cracking on the hemmed edge.

In this study, the high strength steel sheets hollow section was joined by hemming and was examined through an experiment using tensile and fatigue tests and was compared with the hollow section joined by resistance spot welding. 


\section{Hemming process of high strength steel sheets}

Generally the hemming process is performed in three stages. Fig. 1 shows the three stages of the hemming processes. In the 1 st stage the outer panel is bent to $90^{\circ}$ and in the 2 nd stage, the sheet is inverted then bent to $135^{\circ}$. The inner sheet is added in the 3rd stage before the bending of $180^{\circ}$ is performed to join the two sheets.

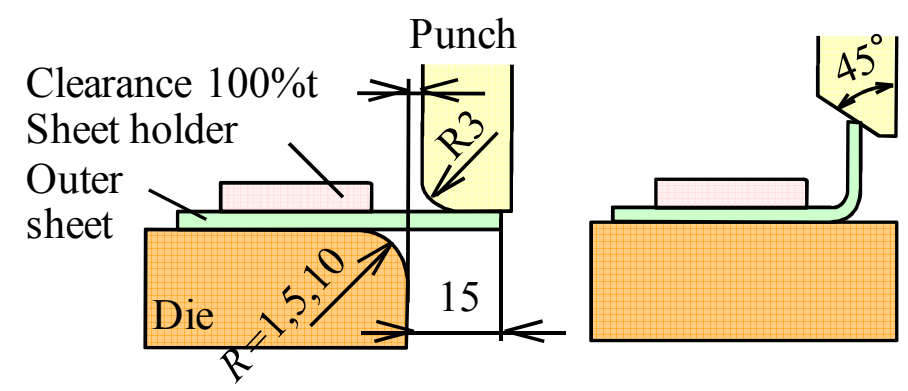

(a) $1^{\text {st }}$ step

(b) $2^{\text {nd }}$ step

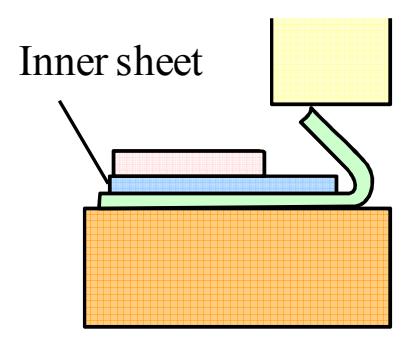

(c) $3^{\text {rd }}$ step

Fig.1. Three stages of hemming process.

The sheets used in this study are two-phased high strength steel sheets. The mechanical properties of the sheets given in Table 1 are according to the tensile test using tensile specimen No. JIS13B .

Table 1. Mechanical properties of the hemmed sheets.

\begin{tabular}{llll}
\hline Sheets & JSC590YN & JSC780YN & JSC980YN \\
\hline Thickness [mm] & 1.22 & 1.22 & 1.23 \\
Tensile strength [MPa] & 628 & 813 & 1026 \\
Elongation [\%] & 22.7 & 17.3 & 14.7 \\
Reduction in area [\%] & 63 & 56 & 53 \\
$n$-value & 0.11 & 0.10 & 0.07 \\
\hline
\end{tabular}

\section{Tensile and Fatigue Strength of Joints}

The joins of the hollow section after the tensile test for the resistance spot welding and hemming are shown in Fig. 2. For the resistance spot welding, the failure occurred at the upper sheet around the welded spot before. The upper sheet tore apart and was separated from the lower sheet. Whereas, for the hollow section joins using the hemming method, the flange portion that joined the inner sheet and outer sheet was opened and deformed during the tensile test and the sheets separated and came out. There was no crack or fracture occurred on the hemmed sheet.

The load-stroke curve of the tensile test for the hollow section joins using the resistance spot welding and the hemming process is shown in Fig. 3. For the resistance spot welding, one side of the weld was broken at the stroke of $15 \mathrm{~mm}$. For the hemming method, flange portion was opened only after the stroke of $22 \mathrm{~mm}$. Although the maximum load of the hollow section using the resistance spots almost doubles the hemming process, it failed earlier than the hemming process. 


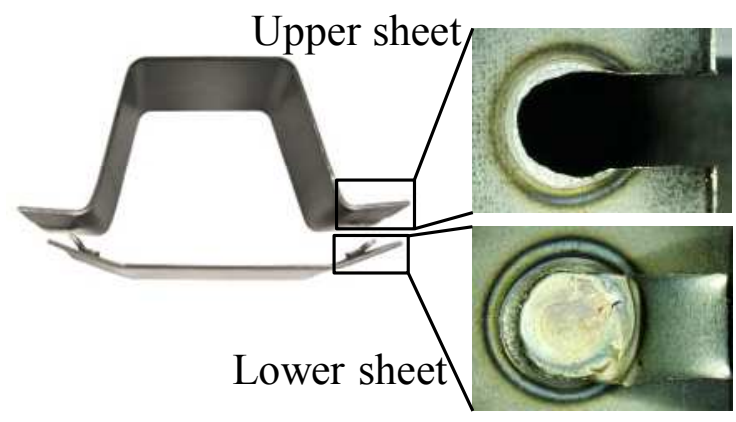

(a) Resistance spot welding

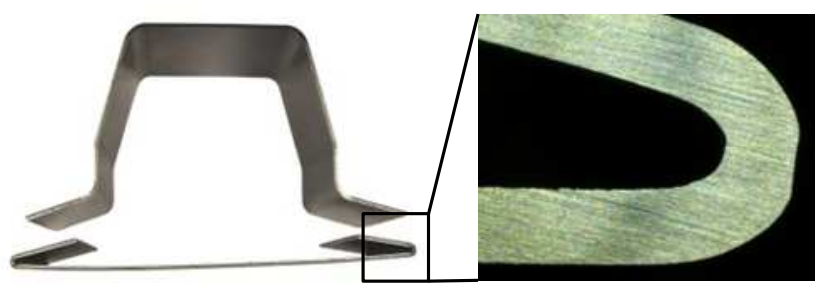

Cross section

(b) Hemming

Fig. 2. Hollow section after tensile test.

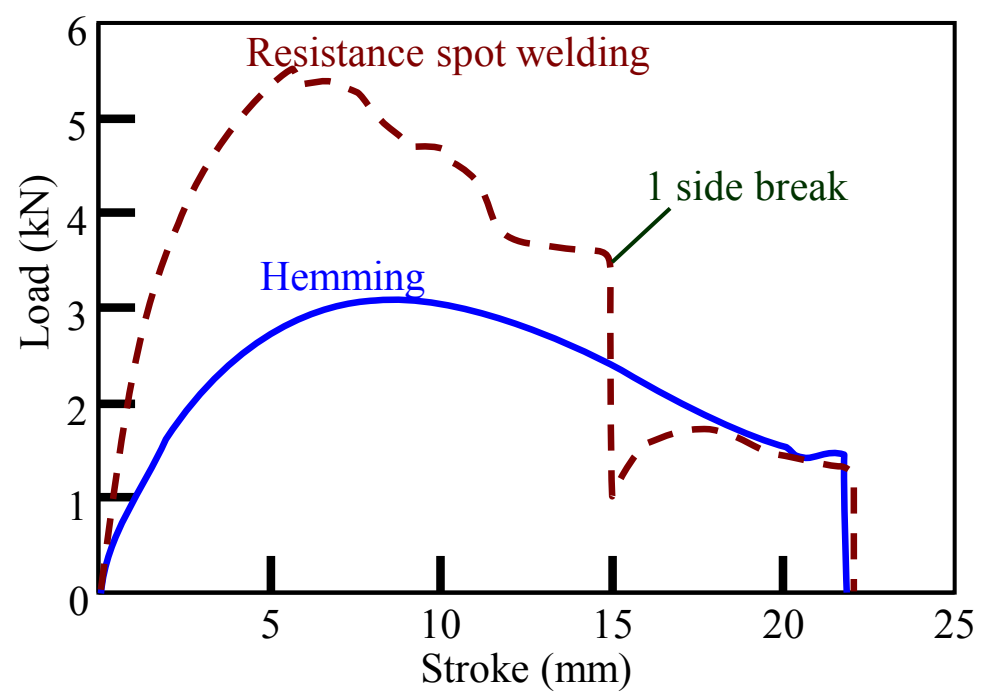

Fig. 3. Load-stroke curve of tensile test for hollow section joins using resistance spot welding and hemming method for JSC890YN.

The maximum load for the hollow section joined by the resistance spot welding and the hemming process is shown in Fig. 4. The load of the resistance spot welding is higher than hemming process for all steel sheets grade. The maximum load for the hemming increased as the strength of the steel sheet increased.

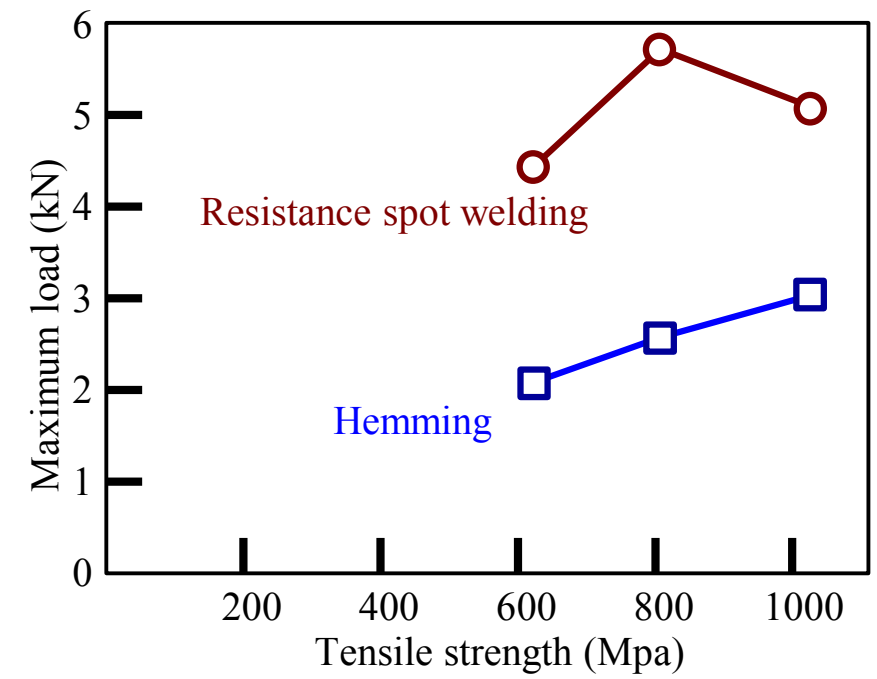

Fig. 4. Maximum load of joint for hollow section joined by resistance spot welding and hemming process. 
The images of the joint of the hollow section for the resistance spot welding and hemming process after the fatigue test are shown in Fig. 5. For the resistance spot welding, the join around the weld cracked and separated the sheets. Whereas for the hemming process, the crack developed from the inner bent portion of the inner sheet and the hemmed was opened and separated the sheet.

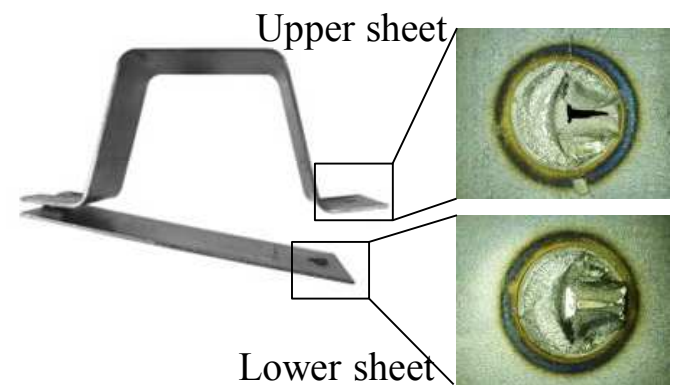

(a) Resistant spot welding

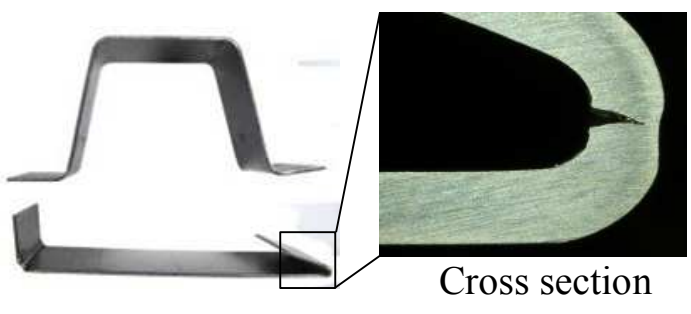

(b) Hemming

Fig. 5. Hollow section after fatigue test for JSC980YN.

The number of cycles to failure in fatigue test of the hollow section joined using resistance spot welding and hemming process is shown in Fig. 6. The number of cycles to failure for the resistance spot welding is higher than the process when the cyclic load is larger. However, when the cyclic load is lower, the difference of the number of cycles to failure for both became smaller and almost the same. The cyclic load of the hemming process was the same when the comparing the cyclic load for the number of cycles reached $10^{7}$ times, the hemming process was higher for the steel sheet grade $780 \mathrm{MPa}$ and the same load for the $980 \mathrm{MPA}$ steel sheet grade. It showed that the fatigue property for the hollow section joins using the hemming process was the same and better at the lower cyclic load.

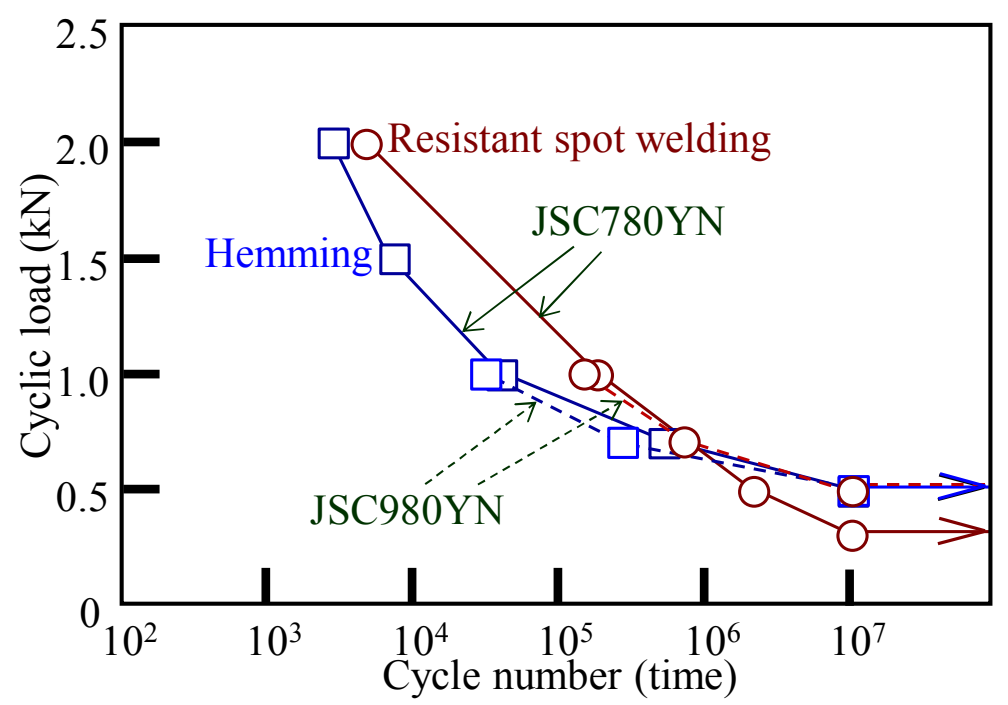

Fig. 6. Fatigue strength of the hollow section.

\section{Conclusions}

The high strength steel sheets with different strength were hemmed to join 2 different sheets. The punch with stopper was employed in the 3rd stage of the hemming processes. The high strength steel sheet was successfully hemmed and the occurrence of crack on the hemmed sheet was prevented. An experimental study of the hollow section joined by resistance spot welding and hemming process was performed. The high strength steel hollow sections joined by the hemming process and resistance spot welding were examined by tensile and fatigue tests. The hollow section 
having hemmed join failed at higher strokes compared to resistance welding for the tensile test but showed better performance at lower cyclic load for the fatigue test. Since the hollow section with hemmed joins was overlapping, the strength became greater than the resistance of spot welding joins.

\section{References}

[1] Merklein, M., Allwood, J.M., Behrens,B.-A., Brosius,A., Hagenah,H., Kuzman,K., Mori,K., Tekkaya, A.E., Weckenmann, A., Bulk forming of sheet metal, CIRP Annals - Manufacturing Technology 61(2) (2012) 725-745.

[2] Hamedon, Z., Mori, K., Abe. Y., In-situ measurement of three-dimensional deformation behaviour of sheet and tools during stamping using borescope, Journal of Materials Processing Technology 214(4) (2014) 945-950.

[3] Mori, K., Abe, Y., Suzui, Y., Improvement of stretch flangeability of ultra-high strength steel sheet by smoothing of sheared edge, Journal of Materials Processing Technology 210(4) (2010) $653-659$.

[4] Abe, Y., Mori, K., Norita, K., 2013. Gradually contacting punch for improving stretchflangeability of ultra-high strength steel sheets, CIRP Annals - ManufacturingTechnology 62(1) (2013), 263-266.

[5] Maeno, T., Mori, K., Hamedon, Z., Hot bending of titanium alloy sheet using resistance heating, Proceedings of the 4th International Conference on Metal Forming 2012. 